\title{
Effective Combination of Incisional Negative Pressure Wound Therapy and Radical Reconstructive Surgery in the Treatment of Post-Sternotomy Mediastinitis Caused by Methicillin Resistant Staphylococcus aureus
}

\author{
Aref Rashed ${ }^{1}$, Ágnes Beledii ${ }^{1}$, Nasri Alotti ${ }^{1}$ and Zsofia Verzar ${ }^{2}$ \\ ${ }^{1}$ Department of Cardiac Surgery, St Rafael Zala County Hospital, Europe \\ ${ }^{2}$ Department of Emergency Medicine, Pecs University of Science, Europe
}

Received: February 23, 2018; Published: March 01, 2018

*Corresponding author: Aref Rashed, Department of Cardiac Surgery, St Rafael Zala County Hospital, Zrinyi M Street 1, 8900 Zalaegerszeg, Hungary, Europe, Tel: 3692507500; Fax: 3692507500; Email: aref.rashed.szv@zmkorhaz.hu

\begin{abstract}
Although rare, post-sternotomy mediastinitis is still a major concern after open heart surgery. Contamination with multi-resistant pathogens is a serious problem, as they fall outside the spectrum of the generally applied antimicrobial prophylaxis. Along with radical surgery, incisional negative-pressure wound therapy may be useful in preventing reinfection. We present a case of a 68-year old woman who underwent open heart surgery and developed post-sternotomy mediastinitis due to methicillin-resistant Staphylococcus aureus. Intravenous antibiotic therapy with multiple sternum-preserving surgical debridement was insufficient to decontaminate the wound and achieve proper healing. After radical surgical debridement and reconstruction in combination with incisional negative-pressure wound therapy, final wound healing occurred with no sign of reinfection in the follow-up period. Combining incisional negative-pressure wound therapy with radical surgical debridement and reconstruction may be the most appropriate way to decontaminate wounds infected by multiresistant organisms.
\end{abstract}

Keywords: Methicillin-Resistant Staphylococcus aureus; Negative Pressure Wound Therapy; Post-Sternotomy Mediastinitis

\section{Introduction}

Multi-resistant pathogens are a concern and great burden in surgical-site infections after open-heart surgery, and routine perioperative antibiotic prophylaxis provides no protection against those organisms. Radical surgical debridement and reconstruction results in the development of dead spaces, which can facilitate reinfection in these difficult-to-treat wounds. Here we present a case where a combination of incisional negative-pressure wound therapy (NPWT) and radical surgery led to wound decontamination, early dead-space obliteration and drain removal.

\section{Case Report}

A 68-year old women underwent coronary artery bypass grafting and aortic valve plasty through a median sternotomy with left internal thoracic artery harvesting. She was on medication for non-insulin dependent diabetes mellitus and chronic obstructive pulmonary disease. Her body mass index was $33 \mathrm{~kg} /$ $\mathrm{m}^{2}$, and preoperative nasal screening for methicillin-resistant
Staphylococcus aureus (MRSA) was negative. She was discharged on the 9th post-operative day with a properly healing sternal wound, stable sternum, and nearly normal C-reactive protein (CRP; $16.4 \mathrm{mg} / \mathrm{L}$ ). On the 24 th postoperative day, she was readmitted due to an excessive pasty discharge from her sternal wound. Her CRP was elevated $(153 \mathrm{mg} / \mathrm{L})$ at that time. Samples obtained from the wound for microbiological evaluation revealed the presence of MRSA. In an attempt to decontaminate the wound and prepare it for final surgical reconstruction, we surgically debrided and irrigated it. Open-wound treatment was continued with NPWT (Vivano, Hartmann Ricco LTD, Budapest, Hungary) and the initiation of antibiotic therapy with vancomycin $(2 \times 1$ g daily $)$.

The NPWT dressings were regularly changed in the operating room every 3 days, and further wound debridement was always performed. After 2 weeks of treatment, the wound cultures showed no bacterial growth. Therefore, the sternum was rewired and irrigation-suction drainage with a dilute Betadine solution was 
initiated. Mechanical ventilation was required for 2 days due to hypoxaemia. One week later, wound discharge appeared again, so we reopened the wound and continued the NPWT. The microbiological samples still showed MRSA contamination. The NPWT continued for 38 days, but despite the intravenous vancomycin therapy, decontamination of the wound was not achieved in this period. We decided to perform a radical decontaminative surgery and discontinued the NPWT two days prior to the operation. During this time, all the infected tissues, including the sternum and retrosternal space, showed various extents of biofilm development that could not be seen during the NPWT.

During the operation, all tissue that was covered by biofilm, including the entire sternum, was totally removed. The sternum was completely resected to the costal cartilages, which were subsequently covered by various amounts of periosteum. To cover the post-debridement defect and improve the perfusion status of the wound, bilateral pectoral muscle advancement flaps were used. Finally, the skin and underlying soft tissue were closed with interrupted sutures in one layer. Six Redon drains were left in the wound, 3 under and 3 over the pectoral muscle flaps. Incisional NPWT was applied for 10 days (Figure 1). The Redon drains were removed on the $3^{\text {rd }}$ and $4^{\text {th }}$ postoperative days as the discharge decreased below $30 \mathrm{~mL} /$ day. Two consecutive microbiological samples obtained from the drain discharge showed no bacterial growth. Computed tomography images acquired 3 months after the surgery showed the mediastinum covered by muscle flaps with no signs of inflammation (Figure 2). One year after the operation, the patient was doing well, had no complaints, no pain, and expressed no restrictions during physical activity.

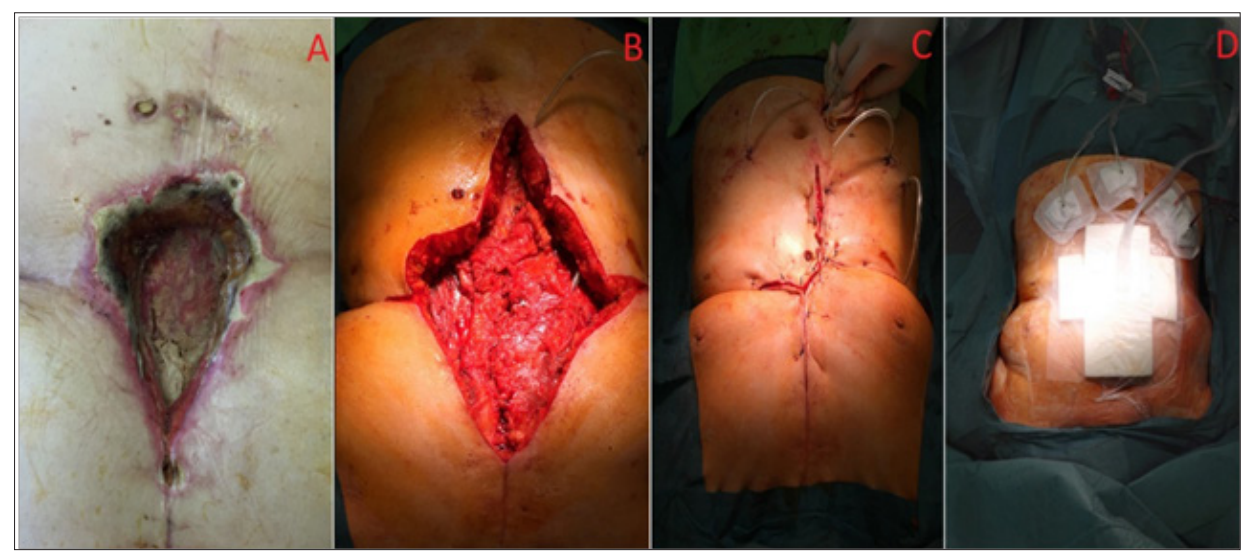

Figure 1: intraoperative seen. A: Biofilms in the sternal wound after cessation of NPWT for two days. B: Radical surgical debridement, bilateral pectoram muscle flap plasty. C: Final closure of surgical wound. D: Incisional NPWT over closed wound.

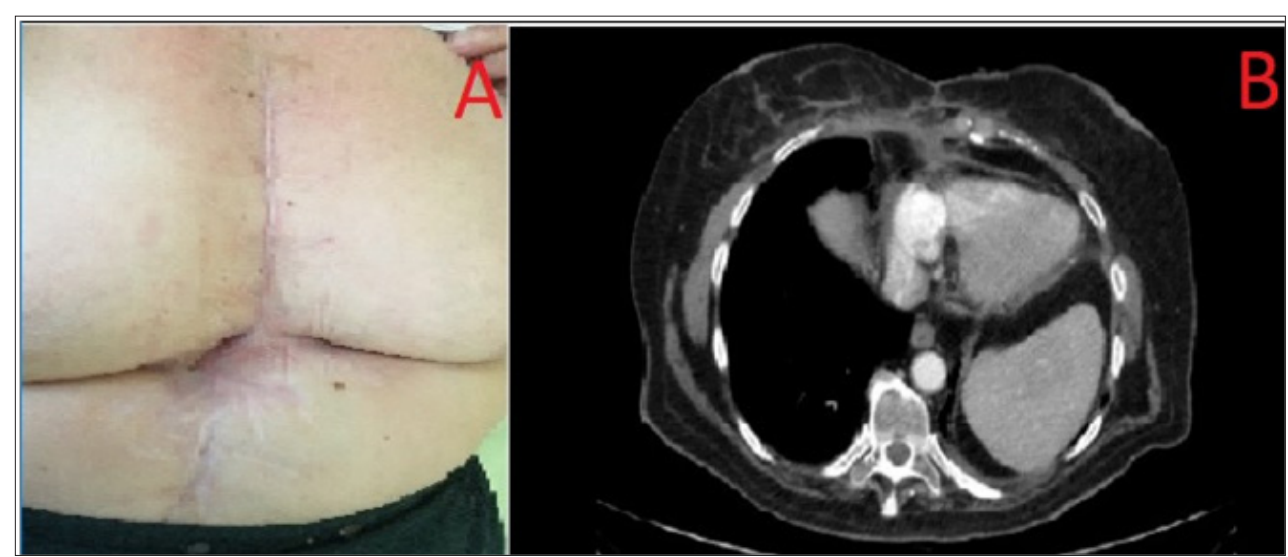

Figure 2: (a) Sternal wound after 3 months of surgical reconstruction. (b) Three months after surgical reconstruction, pectoral muscle flaps cover the anterior mediastinum.

\section{Discussion}

Post-sternotomy mediastinitis is still a major concern after open heart surgery, with a considerable impact on morbidity, mortality, and long-term survival [1-3]. Staphylococcus aureus is the most commonly cultured organism from sternal wounds. No definitive risk factors have yet been identified to screen and identify the patients who might be expected to have a high risk of developing post- sternotomy mediastinitis due to S. aureus infection [4]. Methicillinresistant $S$. aureus cultured from sternal wounds leads to poorer outcomes with regard to treatment failure and actual survival. Some have reported a decreased incidence of MRSA infections in cardiac surgery after proper nasal screening and decolonization [5]. The Society of Thoracic Surgeons Practice Guidelines [6] recommend cephalosporin for perioperative antibiotic prophylaxis 
in cardiac surgery, which provides no protection against MRSA. The most commonly administered antibiotic used to treat MRSA wound infections is vancomycin. However, radical surgical debridement and reconstruction may be the only effective method to successfully decontaminate these wounds.

In our case, multiple sternum-preserving debridements did not lead to wound decontamination, and a failure of treatment was the final result. Radical surgery with the removal of all infected foci was the only feasible procedure to achieve this goal. Pectoral muscle flaps are well-vascularized and serve to cover the defects after a radical surgical debridement, in addition to improving perfusion and antibiotic penetration into the reconstructed wounds. Dead spaces should be drained to avoid the development of seroma and prevent infection. A novel method to reach this goal is by applying incisional NPWT over the reconstructed wound [7]. This can lead to the accelerated obliteration of dead spaces and earlier removal of Redon drains, which could result in a shorter hospitalization time. Radical debridement, or decontaminative surgery, is usually needed when dealing with wounds contaminated by multiresistant pathogens. Antibiotic penetration can be questionable afterwards, and pectoral muscle flaps may be the best route for their delivery to the wounds. Incisional NPWT may also accelerate the obliteration of dead spaces and surgical drain removal, decreasing the rates of reinfection.

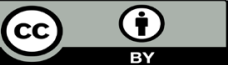

This work is licensed under Creative Commons Attribution 4.0 License

Submission Link: http://biomedres.us/submit-manuscript.php

\section{References}

1. Omran AS, Karimi A, Ahmadi SH, Davoodi S, Marzban M, et al. (2007) Superficial and deep sternal wound infection after more than 9000 coronary artery bypass graft (CABG): incidence, risk factors and mortality. BMC Infect Dis 7: 112.

2. Filsoufi F, Castillo JG, Rahmanian PB, Broumand SR, Silvay G, et al. (2009) Epidemiology of deep sternal wound infection in cardiac surgery. J Cardiothorac Vasc Anesth 23(4): 488-494.

3. Karra R, McDermott L, Connelly S, Smith P, Sexton DJ, et al. (2006) Risk factors for 1-year mortality after postoperative mediastinitis. J Thorac Cardiovasc Surg 132(3): 537-543.

4. Kanafani ZA, Arduino JM, Muhlbaier LH, Kaye KS, Allen KB, et al. (2009) Incidence of and preoperative risk factors for Staphylococcus aureus bacteremia and chest wound infection after cardiac surgery. Infect Control Hosp Epidemiol 30(3): 242-248.

5. Carrier M, Marchand R, Auger P, Hébert Y, Pellerin M, et al. (2002) Methicillin-resistant Staphylococcus aureus infection in a cardiac surgical unit. J Thorac Cardiovasc Surg 123(1): 40-44.

6. Engelman R, Shahian D, Shemin R, Guy TS, Bratzler D, et al. (2007) Workforce on Evidence-Based Medicine, Society of Thoracic Surgeons. The Society of Thoracic Surgeons practice guideline series: Antibiotic prophylaxis in cardiac surgery, part II: Antibiotic choice. Ann Thorac Surg 83(4): 1569-1576.

7. Rashed A, Frenyo M, Gombocz K, Szabados S, Alotti N (2017) Incisional negative pressure wound therapy in reconstructive surgery of poststernotomy mediastinitis. Int Wound J 14(1): 180-183.

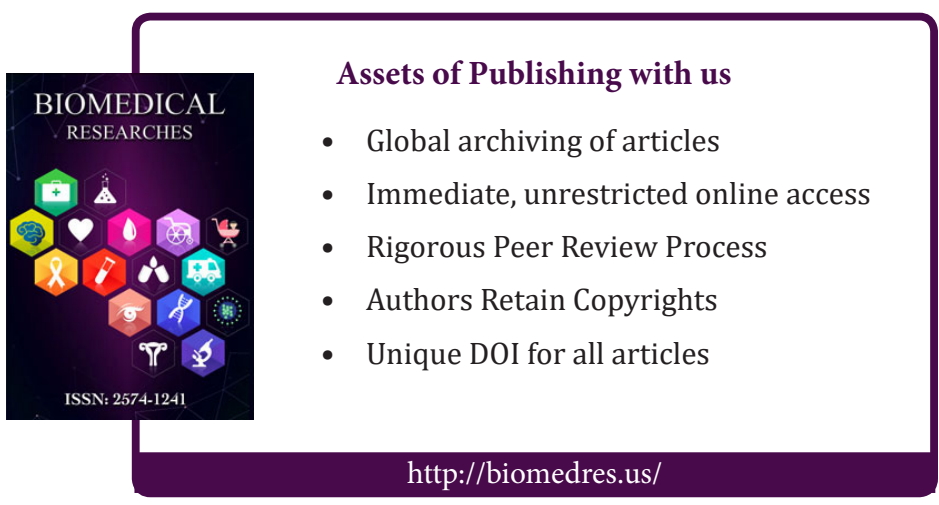

